\title{
Last Glacial Maximum habitat change and its effects on the grey-headed flying fox (Pteropus poliocephalus Temminck 1825)
}

\author{
J. G. Luly
}

School of Earth and Environmental Sciences, James Cook University, Townsville, Queensland jonathan.luly@jcu.edu.au

\section{David Blair}

School of Marine and Tropical Biology, James Cook University, Townsville, Queensland

\section{Jennifer G. Parsons}

School of Marine and Tropical Biology, James Cook University, Townsville, Queensland

\section{Samantha Fox}

School of Marine and Tropical Biology, James Cook University, Townsville, Queensland; Department of Primary Industries and Water, Hobart, Tasmania

\section{Jeremy VanDerWal}

School of Marine and Tropical Biology, James Cook University, Townsville, Queensland; Centre for Tropical Biodiversity and Climate Change, James Cook University, Townsville, Queensland

\section{Introduction}

The grey-headed flying fox (Pteropus poliocephalus) is a large phytophagous bat found in coastal and near-coastal eastern Australia, from Mackay in the north to Geelong in the south (Parsons et al. 2008; Roberts et al. 2008). It is among the best known of the Australian flying foxes. Eby (1991), Parry-Jones and Augee (1991, 1992, 2001), Tidemann and Nelson (2004), McDonald-Madden et al. (2005), Parris and Hazell (2005), and Williams et al. (2006) documented aspects of P. poliocephalus ecology. Eby (1991) and Parry-Jones and Augee (2001) focused on movements between colony sites and feeding areas, while Tidemann and Nelson (2004) demonstrated long-distance movements between colonies. Breeding biology was dealt 
with by Martin et al. (1985), O'Brien (1993), and Fox (2006), and conservation status was summarised by Dickman and Fleming (2002).

The application of molecular tools to flying-fox phylogeny and phylogeography is in its infancy but the approach has obvious potential to solve many of the intractable problems posed to traditional methodologies by this elusive nocturnal species. Among other uses, analyses of genetic diversity can indicate whether a species has undergone changes in population size. In this paper, we place the molecular evidence for population change into a palaeoenvironmental context to gauge the antiquity of any such change and assess its implications for understanding long-term flying-fox responses to contemporary habitat fragmentation and habitat change.

\section{The grey-headed flying fox}

The grey-headed flying fox is a species that inhabits coastal forests and woodlands. The northern limit of its range is near Mackay in northern Queensland, and until recently, it was found as far south as Mallacoota in far eastern Victoria (Figure 1). Although a sporadic visitor to Victoria for at least 100 years, a small permanent population became established in Melbourne in 1986. This southwards extension of range was attributed to the development of a warm, humid urban microclimate associated with the growth of the city (Parris and Hazell 2005). Williams et al. (2006) emphasised the capacity of the rich and reliable food sources provided in urban landscapes to sustain a permanent population of flying foxes.

Inland limits for the species are not clearly defined, and P. poliocephalus is found episodically from the coast to the western slopes of the Great Dividing Range, coinciding approximately with the $800 \mathrm{~mm}$ isohyet (Churchill 2008). The altitudinal range is similarly ill-defined, though migrants pass through the Stanthorpe district of southern Queensland (elevation approximately $870 \mathrm{~m}$ ) and the flying foxes are occasional summer visitors to Canberra at an elevation of approximately $600 \mathrm{~m}$ (D. Hansman pers comm.; J. Luly pers obs.). At present, the core range of the species lies in the tall eucalypt forests of coastal and northern New South Wales (Law et al. 2002).

The grey-headed flying fox is a canopy feeder, consuming pollen, nectar, flowers, fleshy fruit and occasionally leaves (Eby 1998; Williams et al. 2006). Nectar and pollen are most often from sclerophyllous forests (dietary studies indicate a preference for Eucalyptus and Melaleuca), while the fruit component of the diet tends to be provided by rainforest-related taxa, such as figs, and in the modern setting, urban plantings and orchards. Reliance on nectar and pollen imposes significant constraints on P. poliocephalus. Spatial and temporal heterogeneity of flowering in eucalypt-dominated sclerophyllous forests is the norm (Law et al. 2000, 2002), obliging flying foxes to forage widely. Nocturnal foraging may involve round trips of up to $50 \mathrm{~km}$, though most foraging activity occurs within a $20 \mathrm{~km}$ radius (or less) of the daytime roost (Eby 1991; Tidemann 1999). Individual bats have been shown to make periodic movements of at least $2000 \mathrm{~km}$, covering more than 4 degrees of latitude over the course of several months (Tidemann and Nelson 2004). Despite a capacity to forage over large distances, the phenology of key food trees imposes annual periods of significant food shortage, especially in late winter or early spring (Law et al. 2002). Species such as Eucalyptus tereticornis, E. robusta, E. siderophloia and Melaleuca quinquenervia (northern New South Wales) and E. melliodora and E. albens (western slopes) are key food sources that sustain $P$. poliocephalus through the winter-spring famine and the exigencies of the birthing season when females produce their single young (Law et al. 2002). In poor years, particularly in times of drought, food shortages lead to reduced reproductive success and increased mortality (Eby 1999; Eby et al. 1999). Conversely, P. poliocephalus, like other pteropodid bats, is unable to 


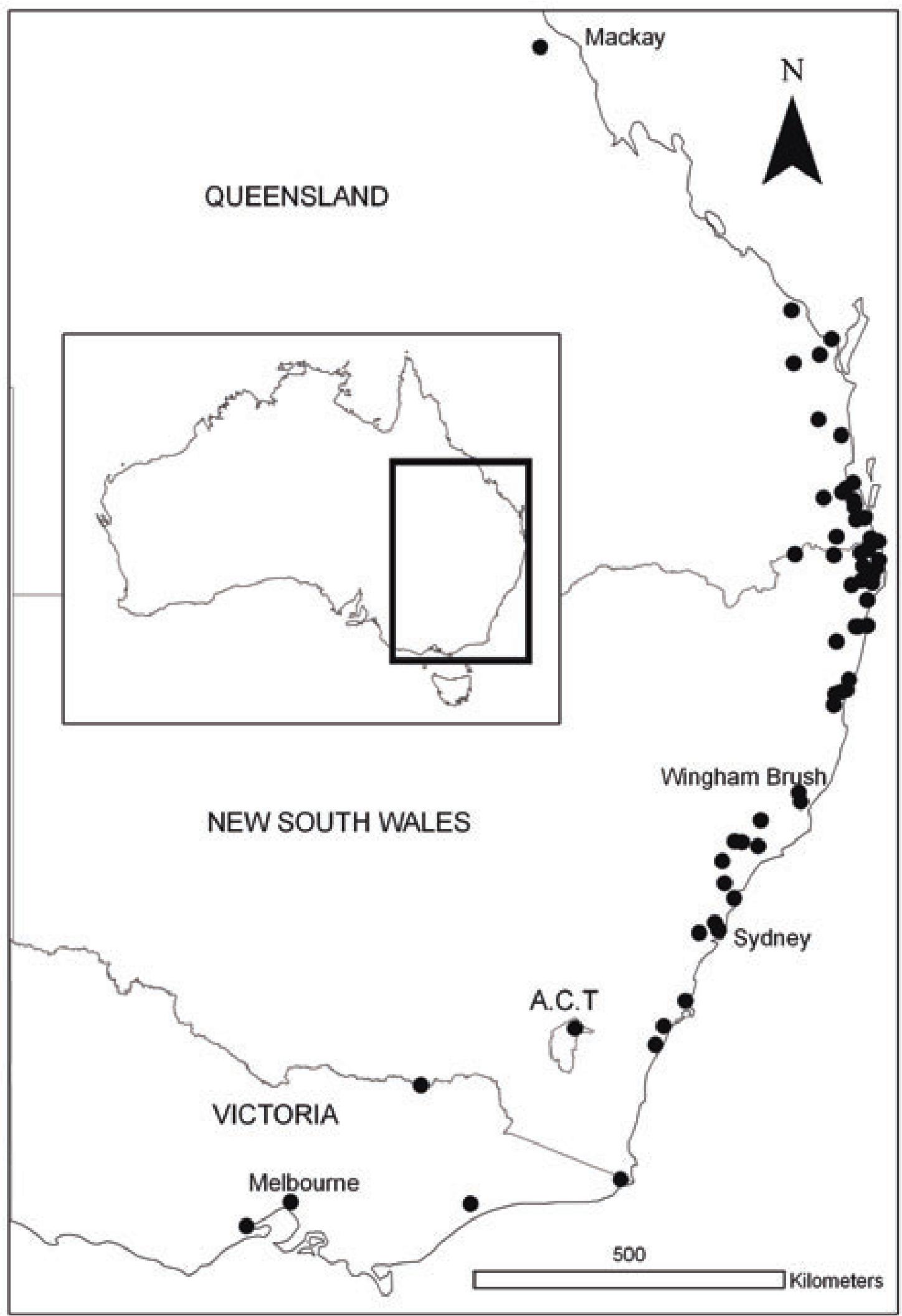

Figure 1. Current distribution of the grey-headed flying fox (Pteropus poliocephalus). Sampled localities are marked 
increase its reproductive output in times of plenty, though a greater proportion of juveniles may survive their first year. Accounts of opportunistic recruitment (Tidemann 1999), which would allow rapid reproductive response to good seasons or routinely replace young lost early in the breeding season, are mistaken (Fox et al. 2008).

Local populations of P. poliocephalus, and other flying foxes are sensitive to fluctuations in environmental conditions. Mass mortality events attributed to excessive heat (Ratcliffe 1932; Welbergen et al. 2008), cold (J. Maclean pers comm. 2008) and starvation (Ratcliffe 1932) have been noted, as well as a number of instances of spontaneous mass abortion of near-term young (Parsons pers obs.; J. Maclean pers comm. 2007). Grey-headed flying-fox populations have a low intrinsic capacity to increase (Martin and Mcllwee 2002; Mcllwee and Martin 2002) and numbers are presently in decline. Writing in 1931, Ratcliffe suggested flying-fox numbers had decreased by approximately $50 \%$ in eastern Australia since European settlement as a result of habitat clearing and, possibly, competition with the black flying fox (Pteropus alecto). More recent censuses suggest there has been a $30 \%$ decline in $P$. poliocephalus populations in the 10 to 15 years before 2000 (Richards 2000), as a result of clearing of habitat, culling by orchardists, losses to powerlines and barbed-wire fencing, as well as climatic extremes. The decline has almost certainly continued since then. The most recent reliable estimate based on colony census (Eby 2004) suggests the total grey-headed flying-fox population to be approximately 425,000 animals.

These data were sufficient to convince the IUCN, the Commonwealth and the states of New South Wales and Victoria to list $P$. poliocephalus as vulnerable on the IUCN Red List (2008), under the Environment Protection and Biodiversity Act 1999 (Commonwealth), the Threatened Species Conservation Act 1995 (NSW) and the Fauna and Flora Guarantee Act 1988 (Victoria).

In summary, $P$. poliocephalus is an extremely mobile species with a capacity to exploit spatially and temporally variable resources but which experiences significant resource bottlenecks on inter-seasonal and intra-seasonal timescales. The species has a demonstrated sensitivity to clearance of habitat and a low intrinsic capacity to recover from population declines. As a consequence, it is likely to be severely affected by the climatically modulated changes in vegetation predicted for the near-term future. It may well also have suffered severely from habitat change accompanying climatic changes in the past.

\section{Quaternary climate and habitat change}

\section{Palaeoclimate}

Predicted climatic change and instability is considered to pose a significant threat to a panoply of species in Australia, including flying foxes (Welbergen et al. 2008). Changes anticipated over the next century are relatively small in magnitude and are overlaid on a 10,000-year Holocene history remarkable for its stability and predictability. Before 10,000 BP, stability and predictability were far from the norm and severe climatic stress influenced individual species and the habitats they occupied. The most recent period of extreme climatic stress is at and around the Last Glacial Maximum between 24,000 BP and 19,000 BP (Barrows et al. 2002). This period was the culmination of a slide from warm, interglacial conditions centering on 125,000 BP, to cold, dry climates of a glacial period. The changing climate drove radical alterations in continental area, hydrology, landscape function and biota not experienced in the Holocene.

The magnitude of climate changes during the Pleistocene is estimated through analyses of proxy data and application of numerical models, and the timing estimated with reference to radiometric dating of climate-sensitive geological and geochemical sequences on land and in the ocean. For the most part, there is convergence between the findings of proxy-based and 
model-based reconstructions of palaeoclimate. Estimates of temperatures at the Last Glacial Maximum range between $6^{\circ} \mathrm{C}$ and $9^{\circ} \mathrm{C}$ below current values in inland Australia (Miller et al. 1997), $8^{\circ} \mathrm{C}$ to $9^{\circ} \mathrm{C}$ in the Snowy Mountains (Galloway 1965) and about $5^{\circ} \mathrm{C}$ in the tropical north (Kershaw 1995, though rather equivocally). Proximity to the ocean is likely to have moderated the underlying temperature depression in coastal areas, however sea-surface temperatures were also lower in extra-tropical latitudes than they are today, and models that incorporate the influence of the ocean indicate that reductions of the order of $3^{\circ} \mathrm{C}$ might have been typical in coastal localities (Hope 2005).

Evidence from lake levels (e.g. Bowler and Hamada 1971; Chen et al. 1993; Bowler et al. 2001; Magee et al. 2004,), speleothems (Ayliffe et al. 1998) sand dunes and dust (Ash and Wasson 1983; Wasson 1983; Hesse 1994; Hesse et al. 2003), and vegetation (Hope 1994; Kershaw 1995) all indicates that cold conditions at the Last Glacial Maximum were accompanied by a drier climate. Quantitative estimates of rainfall change are less amenable to precise delineation than palaeotemperature, as analyses of palaeo-water balance are complicated by interactions between precipitation, temperature, wind velocity and vegetation cover. Wide bands of uncertainty are attached to figures presented in all studies. Estimates of Last Glacial Maximum rainfall based on vegetation suggest effective rainfall in the tropics was lower than modern values by about 40\% (Kershaw 1986; Thomas et al. 2001) and 50\% or more in southern Australia. Estimates based on closed lake systems, the so-called rain-gauge lakes, tend to be rather higher, 50\% reductions being not unusual (Luly 1993; Thomas et al. 2001).

Additional moisture stress was applied to vegetation during Last Glacial Maximum times by reduced levels of atmospheric carbon dioxide (Barnola et al. 1987), which acted to markedly reduce water-use efficiency in C3 plants, notably trees. Farquhar (1997) noted that, with the observed Last Glacial Maximum $\mathrm{CO}_{2}$ concentration of about $180 \mathrm{ppm}$, half the pre-industrial concentration of recent times, water-use efficiency would also be half that expected in the latest part of the Holocene. In essence, this means that any given quantum of photosynthetic activity at the Last Glacial Maximum would require twice the water it would at $\mathrm{CO}_{2}$ levels seen in pre-industrial modern times, adding a layer of physiological drought to the climatic drought imposed at the Last Glacial Maximum.

\section{Last Glacial Maximum vegetation}

The fossil record of vegetation at the Last Glacial Maximum is sparse but still presents a clear picture of vegetative responses to the prevailing climate. Most sites preserving a record of Last Glacial Maximum vegetation indicate widespread occurrence of treeless, semi-steppe vegetation, sparse grassland or extremely open cool-climate savanna.

Key sites in, or near, the southern portions of the modern range of the grey-headed flying fox include Lake George (Singh and Geissler 1985), sites in western Victoria (e.g. McKenzie and Kershaw 2000; Cook 2009), Bass Strait (Hope 1978; D'Costa et al. 1993; Harle 1997) and the Pilliga Scrub (Dodson and Wright 1989). In the northern portion of the grey-headed flying-fox range, sites on the Bunya Mountains (Moravek unpubl.) and Fraser Island (Longmore 1997; Longmore and Heijnis 1999) also demonstrate radical reductions in tree cover at and immediately following the Last Glacial Maximum. Severe thinning (cover reduced to $20-40 \%$ of modern values) of vegetation around that time can also be inferred from formation or re-activation of linear dunes in places, such as the Blue Mountains, East Gippsland and Tasmania, that are currently stabilised by forest (Ash and Wasson 1983; Wasson 1983; Hesse et al. 2003). The sparsity of eucalypts in Last Glacial Maximum landscapes is well illustrated by mean percentages of eucalypt pollen in all samples from southeastern Australian sites at selected time slices (Kershaw 1995). Eucalypt pollen comprises about $42 \%$ in samples from pre-European modern-day 
vegetation and a mere 7\% in the Last Glacial Maximum flora. These data, in the sense of indicating sensitivity of eucalypts to climatic change, are consistent with the results of bioclimatic modelling presented by Hughes et al. (1996), who argued that eucalypts will be significantly affected by the relatively minor temperature increases posited for an anthropogenically warmed greenhouse climate.

It is self-evident that areas of refugial woody vegetation persisted throughout the last glacial cycle, otherwise woody vegetation and the organisms depending on it would now be extinct. Sites which appear to have been close to arboreal refugia, such as Lake Baraba (Black et al. 2006) or Boulder Flat (Kenyon 1989), rarely exhibit an abundance of pollen from eucalypts or other food plants used by P. poliocephalus. That said, the sporadic occurrence of low-altitude populations of montane species such as Eucalyptus pauciflora in contemporary Australia, and the mixed ecological affinities of vertebrate fossils found in Last Glacial Maximum sites lead Hope (1994), with support from Kershaw (1995) and Hope et al. (2005), to suggest that Australia then exhibited a complex mosaic of vegetation occupying locally protected sites on a generally low-relief landscape, rather than a wholesale downslope movement of altitudinally zoned vegetation such as in Papua New Guinea, Europe and the United States. This messy series of patches could be exploited by a highly mobile animal like the grey-headed flying fox, allowing survival but not prosperity.

\section{The continental shelf}

The Last Glacial Maximum coincided with a fall in sea level of 120-130 m (Yokoyama et al. 2001), exposing most of the continental shelf. Extensive areas were exposed on the Queensland Plateau in the north of the modern range of P. poliocephalus and in what is now Bass Strait in the south. Between these areas, the shelf to the $100 \mathrm{~m}$ isobath is rarely wider than $20 \mathrm{~km}$, and Last Glacial Maximum low-sea-level stands would not provide the space needed for extensive forests capable of sustaining a large number of flying foxes. The vegetation of the Bass Strait sector of the shelf was open, comprising grassland, shrub-heath and communities of halophytes (Hope 1978; D’Costa et al. 1993; Harle 1997), none being of much value for the grey-headed flying fox. There is less evidence to reconstruct the vegetation of the Queensland Plateau at low-sealevel times, however long pollen records from Fraser Island (Longmore 1997; Longmore and Heijnis 1999) indicate that although edaphic and hydrological conditions peculiar to sand mass sites influence vegetation responses to climate, tree-dominated vegetation contracted markedly at Last Glacial Maximum times, to be replaced by the shrub-dominated 'wallum' vegetation characteristic of older dune landscapes of the modern island. Eastwards from there, information is scarce, but the trend noted from Fraser Island and places to the north (Torgersen et al. 1988; Moss and Kershaw 2000; Chivas et al. 2001) suggests the prospect is remote that extensive forested habitat suitable for use by the grey-headed flying fox existed on the exposed shelf.

\section{Molecular evidence of population history}

The application of molecular genetic methods to population biology in modern and ancient environments is a recent and rapidly developing field (e.g. Hofreiter and Stewart 2009). Past changes in population size leave signatures in the genome that can be detected by analysis of, for example, alignments of mitochondrial d-loop DNA sequences from many individuals. Here we analyse mitochondrial sequences to investigate past population sizes in P. poliocephalus and seek to correlate this with habitat and environmental histories. 


\section{Methods}

DNA used in this investigation was extracted from 61 grey-headed flying foxes killed by hail and heat stress at Wingham Brush about $250 \mathrm{~km}$ north of Sydney and 55 live animals captured at the Royal Botanic Gardens in Sydney (Divljan 2008). DNA was extracted from tissue cut from the plagiopatagium (Worthington Wilmer and Barratt 1996), using the EDNA HISpEX tissue extraction kit, following manufacturer's instructions. A portion of the mitochondrial d-loop was amplified using PCR primers developed for Pteropus vampyrus by Kevin Olival (Columbia University, New York). Sequencing protocols are presented in Fox et al. (In prep.).

Panmixia (essentially, unrestricted gene flow throughout the range of the species) in the grey-headed flying fox was inferred by Webb and Tidemann (1996) and Fox et al. (In prep.), and as no evidence of restricted gene flow is evident in mitochondrial sequence data (Fox et al. In prep.), samples from Wingham Brush and Sydney are considered to come from a single population. Accordingly, genetic data from both sites were combined in our analyses.

Signatures of changes in population size can be detected in the pattern of pairwise differences among mitochondrial sequences (Rogers and Harpending 1992). A plot of the frequencies of all pairwise differences (mismatch distribution) forms a smooth unimodal curve in populations that have undergone recent growth but not in populations that have been static for long periods or have declined. Parameters were estimated in ArLeQuin (Excoffier et al. 2005) under the sudden expansion model (null model). ArLeQuin is a software package implementing numerous methods for population genetic data analysis. The observed pairwise mismatch distribution was plotted, along with its simulated value under this scenario, and the upper and lower $95 \%$ bounds (20,000 replicates) (Figure 2). The sum of squared deviation (deviation of simulated from observed - SSD) was calculated and tested against that expected under the sudden expansion model. A related statistic, the raggedness index (Harpending 1994), was also calculated. Its significance is tested in a manner similar to that of the SSD. Values for tau $(\tau)$, can be used to estimate the time at which a population started to expand using the equation $\tau=2 u t$, where $t$ is the number of generations since the crest of the expansion and $u$ is the mutation rate per generation per sequence (Rogers and Harpending 1992).

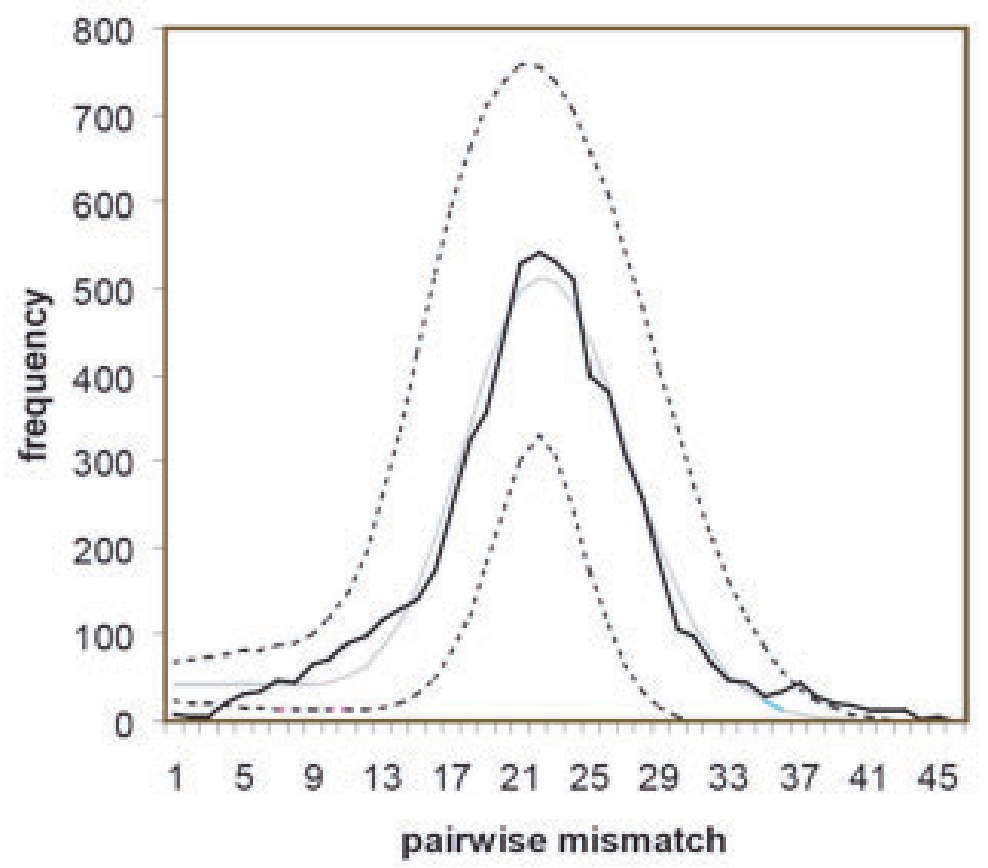

Figure 2. Pairwise mismatch distributions calculated from all available GHFF sequences (solid black line). Upper and lower dashed lines represent the upper and lower 95\% limits based on 2000 replicates in Arlequin. The model frequency is the grey line close to the line for the observed frequencies 
Demographic histories can also be estimated from genealogies (phylogenies) in a Bayesian statistical framework using the program BEAST v1.4.6 (Drummond and Rambaut 2007: http:// beast.bio.ed.ac.uk). Given a set of aligned sequences and a model for sequence evolution, this program samples phylogenetic trees from which simultaneous estimates of a number of demographic and evolutionary parameters are calculated. Runs of MODELTEST (Posada and Crandall 1998) indicated that the $\mathrm{HKY}+\mathrm{G}+\mathrm{I}$ model was the appropriate description of nucleotide substitution to use with BEAST. This model, first developed by Hasegawa et al. (1985), accommodates variation in substitution rate along the length of a sequence and permits a proportion of sites to be invariant. BEAST runs were of sufficient length (typically 30 million or more) to ensure effective sample sizes (ESSs) were always over 100, and usually substantially over this value. Bayesian skyline plots (Drummond et al. 2005) generated by BEAST show changes in effective population size over time, along with credibility intervals. This approach avoids the need to choose a single demographic scenario such as 'constant population size' or 'exponential growth' from the options available in BEAST, and minimises the role of subjective judgement in setting analytical parameters.

The alignment of the 116 sequences was 535 nucleotides in length. Results of all molecular analyses are consistent with expansion in populations of $P$. poliocephalus. For the pairwise-mismatch data, the sum of squared deviation (SSD) value was $0.000584(P=0.768)$, indicating no departure from the unimodal curve that is consistent with population expansion. The analogous Harpending's raggedness index was $0.0014(P=0.9023)$, also consistent with molecular response to population expansion.

Solution of the equation $\tau=2 u t$ requires that one knows either the time since expansion or the mutation rate. Since we know neither with certainty, we explored several possibilities. In light of the palaeoenvironmental data summarised above, we take one very likely starting point for a population expansion to be soon after the culmination of the Last Glacial Maximum at about 18,000 BP. The value for $\tau$ estimated in ArelQuin under the sudden expansion model was 21.887 (confidence interval when $\alpha=0.05,16.568-24.664$ ). The estimated mutation rate $(\mu)$ under this scenario is within the range $86 \%-128 \%$ substitutions per site per million years. Other estimates of mutation rates for the $\mathrm{d}$-loop region of bats are few. Chen et al. (2006) proposed a rate of $20 \%$ per site per million years for the d-loop of Rhinolophus monoceros (Microchiroptera: Rhinolophidae). Applying this to the mitochondrial data from P. poliocephalus gives a time since expansion between 75,562 and 113,974 years BP, a period early in the most recent glacial cycle. Expansion from these dates would imply, quite unreasonably, that Last Glacial Maximum declines in habitat extent and quality had no effect on the bat population.

A Bayesian skyline plot was constructed to show the changes in population size over time (Figure 3). The plot shows effective population size (multiplied by generation time in years) (the Y-axis) and the associated upper and lower 95\% confidence values (highest posterior densities). Plots of mean and median values are very similar in appearance: the median is shown. The time scale on the $\mathrm{X}$-axis in Figure 3 is inferred using the mutation rate estimated assuming population expansion after the Last Glacial Maximum. In this scenario, a marked expansion began at about 10,000 years BP. If a different mutation rate were to be specified, the time scale on the $\mathrm{X}$-axis would be scaled accordingly. For example, if the rate estimated by Chen et al. (2006) of $20 \%$ per site per million years is used, the X-axis would cover about five times the time span shown in Figure 3 and the marked expansion would be pushed back to more than 50,000 years ago. No anthropogenic reduction in $P$. poliocephalus populations can be detected in Figure 3, as the Bayesian skyline plot is derived from phylogenies which require sequences to have mutated during the time scale in question. Mutations presumably have been too few to be detectable during the -200 years since European settlement. 


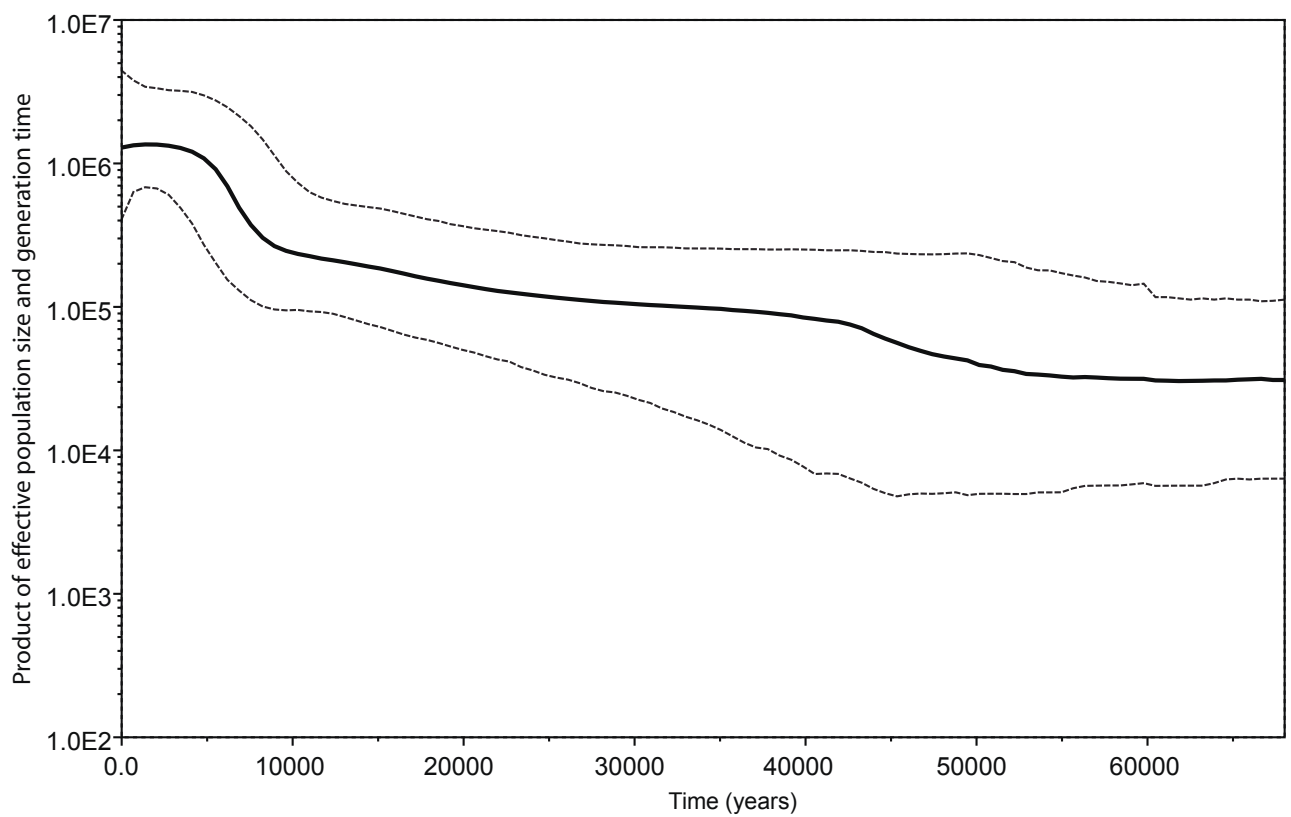

Figure 3. Bayesian skyline plot: Population size change over time is indicated (median value is solid thick line), with 95\% HPD intervals (dashed lines). The X-axis shows time in years back to a specified cut-off (in this case the mean of the root height). Time scales are dependent on mutation rate: the scale shown assumes a mutation rate of $1.06 \mathrm{e}$ 6. The Y-axis (note logarithmic scale) indicates effective population size estimates multiplied by generation time

\section{Bioclimatic modelling}

Climate models developed for modern-day grey-headed flying-fox camps in Australia were projected on to global climate models for the Last Glacial Maximum using the maximum entropy algorithm MAXENT (Phillips et al. 2006), to predict the extent of habitat capable of supporting colonies of $P$. poliocephalus at the Last Glacial Maximum. Maxent is a presenceonly species-distribution modelling approach, for which locations of $P$. poliocephalus roosts were gleaned from the literature (Parris and Hazell 2005) and unpublished data (Parsons et al. In prep.). The environmental correlates used in the models included annual mean temperature, temperature seasonality, maximum temperature of warmest period, minimum temperature of coldest period, temperature annual range, annual precipitation, precipitation seasonality, precipitation of wettest quarter, and precipitation of driest quarter. The surfaces for modern conditions were derived using ANuclim 5.1 software (McMahon et al. 1995) and a nine second digital elevation model (Version 2; Geoscience Australia http://www.ga.gov.au/). We assumed the glacial maximum sea level to be $100 \mathrm{~m}$ below the present level, and maps (Figures $4 \mathrm{a}, 4 \mathrm{~b})$ show the area of continental shelf landward of the $100 \mathrm{~m}$ isobath.

MaXent builds the models, contrasting where a species occurs with the 'background' or pseudo-absences, i.e. presence is definite, whereas 'absence' may reflect true absence or gaps in the data. In this study, 10,000 background points were drawn at random from localities within $1000 \mathrm{~km}$ of known colonies to minimise regional biases in the models (Van Der Wal et al. 2009). Further description of model parameterisation can be found in Parsons et al. (In prep.). Once built, the models were projected on to two global climate models (CCSM and MIROC) for the Last Glacial Maximum $(-21,000 \mathrm{BP})$ at $5 \mathrm{~km}$ resolution. These surfaces were downloaded from Worldclim-1 (www.worldclim.org) and are to this extent independent of the Last Glacial Maximum climatic changes summarised from the Australian palaeoenvironmental literature. As differences between predictions yielded by the two Last Glacial Maximum GCM models were minimal, we chose only to present the results from CCSM, as this gives the more conservative estimate of past distribution (Figure 4a). MAXENT thresholds were set at 0.01 for all analyses. Estimates of abundance or carrying capacity relative to current abundance were 
made by summing the suitability values of the past predictions and contrasting these with the present modelled suitability, as per Van Der Wal et al. (2009).

Perhaps unsurprisingly, given that the models were constructed using the modern distribution of $P$. poliocephalus overlaid on a modern climate surface, they describe the current
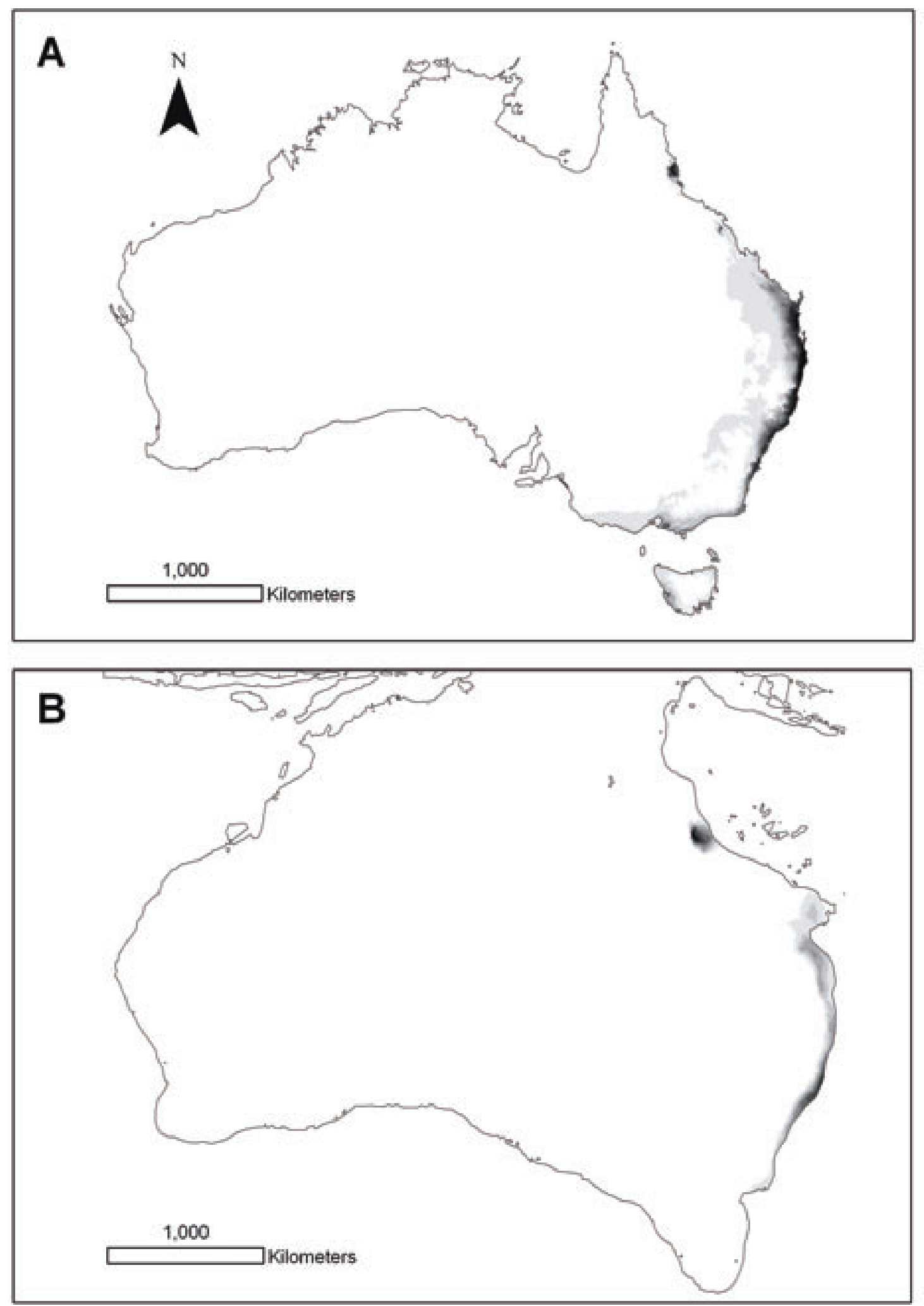

Figure 4. Maxent model of suitable environmental space for grey-headed flying foxes in the current climate (A) using BIOCLIM and at the Last Glacial Maximum (B) using CCSM (Worldclim). Darker areas indicate more suitable environmental conditions 
climatic circumstances of the bat well. There is an outlier of climatically suitable habitat identified on the Atherton Tablelands, approximately $700 \mathrm{~km}$ north of the most northerly known P. poliocephalus colony at Finch Hatton near Mackay. Though anecdotal accounts suggest that very occasional individual P. poliocephalus have been sighted in that region (Parsons pers comm.), the species is not resident there. The most parsimonious explanation for this discrepancy - always assuming that the model is generally applicable - lies in the interactions between P. poliocephalus and the three other species of flying fox (Pteropus conspicillatus, P. alecto and $P$. scapulatus), which occupy a common competitive space. All three species use the same resource base as $P$. poliocephalus, though $P$. conspicillatus and $P$. alecto are more generalist feeders than the nectar-dependent $P$. poliocephalus. Pteropus scapulatus is also a nomadic nectarivore but ranges much further inland and north than the other species (Hall and Richards 2000), and it is likely that the most direct competition is between $P$. poliocephalus and $P$. alecto. Some authors argue that the apparent southwards range extension of $P$. alecto in the $20^{\text {th }}$ century has been at the expense of $P$. poliocephalus (Eby et al. 1999), suggesting that $P$. poliocephalus would find it difficult to colonise an area if $P$. alecto is present. Under these circumstances, successful establishment of a disjunct population of $P$. poliocephalus so distant from the core range of the species seems to be vanishingly unlikely, even if the habitat is suitable.

The CCSM climate models centred on 21,000 BP suggest that habitat for P. poliocephalus decreased radically, to some $33 \%$ of its modern extent, and the carrying capacity of the habitat declined even more spectacularly, to $16 \%$ of the modern-day figure (Figure $4 \mathrm{~b}$ ). The core glacial maximum distribution of $P$. poliocephalus remains focused in central New South Wales, with the envelope of usable bioclimate shifting eastwards on to the continental shelf. In southern Australia, this opens little additional habitat as the shelf is narrow. In southern Queensland, where the shelf widens substantially, modelled habitat exists but is not of high ecological value for the species. The patch of potential habitat available on the Atherton Tablelands remains. However, the gap to be surmounted by any putative colonisation by $P$. poliocephalus is even wider than at present.

\section{Discussion}

Each of the three avenues employed to investigate the likely population history of Pteropus poliocephalus has its own set of assumptions and foibles. Simple conclusions drawn from interpretations of the palaeoenvironmental record are vulnerable to uncertainties related to the biology of the creature in question. This difficulty is well illustrated by the debates that lie behind extinction of the Australian megafauna and the small mammal fauna extirpated during the tenure of European dominance of the continent. In each instance, incomplete appreciation of ecology, breeding biology and habitat requirements hinders efforts to discriminate between the many alternative explanations advanced for their demise.

Similarly, too-literal adherence to conclusions drawn from bioclimatic modelling may yield internally consistent results that are not consonant with what is known of the palaeoenvironmental record for the species or region of interest. A splendid example is provided by Graham et al. (2006), who improved the explanatory power of models seeking to explain the distribution of biodiversity in the wet tropics of Queensland by incorporating Bioclimgenerated layers of historical vegetation to their analyses. The modelled extent of historical vegetation at the Last Glacial Maximum is considerably greater than that reconstructed by palaeoenvironmental methods, in part because focus on climatic controls on vegetation do not capture the effects flowing from pre-European human influence on vegetation and landscape. In our study, modelled habitat potentially suitable for $P$. poliocephalus occurs in the wet tropics region, but there is absolutely no reason to believe that the purported habitat is of use to the species now or has been in the past. 
Finally, the application of molecular methods to historical questions is an innovation adopted with great enthusiasm across a range of disciplines and for a diversity of purposes. The analytical methods are rigorous but interpretation of results retains elements of the subjectivity which characterises analyses of palaeoenvironments by more traditional means. Our analysis of the timing of expansion in populations of $P$. poliocephalus is based on a mutation rate that is high by accepted standards in the field (although comparable with recent estimates for some other vertebrates, e.g. Hay et al. 2008), but which yields results that are consistent with conclusions drawn from modelling and evidence of habitat change drawn from the fossil record. Application of more conservative mutation rates yields ages of expansion that are believable on molecular grounds but cannot be sustained in light of other lines of evidence.

The population history of $P$. poliocephalus is unlikely to be unique to this species. Hints of a Last Glacial Maximum genetic bottleneck can be detected in the spectacled flying fox (Pteropus conspicillatus; Fox 2006) and it would be most surprising if other species were not similarly affected. Flying foxes and other volant species are well equipped to traverse habitat discontinuities and appear to be able to persist in small numbers for significant periods of time by exploiting habitat patches. The density-dependent ecological roles played by flying foxes (McConkey and Drake 2006) may have been significantly disrupted during periods of population contraction and provide an additional, hitherto unsuspected, stressor on community function during glacial episodes.

\section{Conclusions}

Climatic events that culminated at the Last Glacial Maximum produced catastrophic declines in the area of habitat available to the grey-headed flying fox and other species dependent on wooded landscapes, but the effects of these changes on flying-fox populations are conjectural, as the fossil record of all but a very select few species is entirely absent. Molecular explorations of the population history of Pteropus poliocephalus suggest that it has undergone a major expansion; the timing of the expansion cannot be determined with confidence on molecular grounds alone, but in combination with palaeoenvironmental reconstructions and bioclimatic modelling, the timing of likely changes in population can be refined and the extent of population changes quantified. During the Last Glacial Maximum, P. poliocephalus numbers may have fallen to as few as $16 \%$ of the modern population, or approximately 68,000 individuals. The recovery following the Last Glacial Maximum is likely to have coincided with the recovery of forested habitat from about 10,000 BP.

In modern times, $P$. poliocephalus is undergoing a rapid decline in population as a result of human actions. The limited intrinsic capacity to recover from population declines, coupled with the complexity of the causes of contemporary declines and the unpopularity of bats in general and flying foxes in particular, makes $P$. poliocephalus a likely victim of the application of 'ecological triage' (sensu Walker 1992) when it comes to allocation of scarce conservation resources to stem the decline. Our results show that the species has a capacity for long-term survival in fragmented landscapes and give some cause to hope that $P$. poliocephalus may have the genetic resilience to persist at low numbers and to recover if given sufficient time.

\section{Acknowledgements}

J.P. thanks Townsville Airport Pty Ltd, Qantas and Virgin Blue for financial and logistical support. 


\section{References}

Ash, J. E. and R.J. Wasson 1983. Vegetation and sand mobility in the Australian dunefield. Zeitschrift für Geomorphologie N.F., Supplement Band 45:7-25.

Ayliffe, L.K., P.C. Marianelli, K.C. Moriarty, R.T. Wells, M.T. McCulloch, G.E. Mortimer and J.C. Hellstrom 1998. 500 ka precipitation record from southeastern Australia: Evidence for interglacial relative aridity. Geology 26:147-150.

Barnola, J.M., D. Raynaud, Y.S. Koretkevich and C. Lorius 1987. Vostok ice core provides 160,000 year record of atmospheric $\mathrm{CO}_{2}$. Nature 329:408-414.

Barrows, T.T., J.O. Stone, L.K. Fifield and R.G. Cresswell 2001. Late Pleistocene glaciation of the Kosciuszko massif, Snowy Mountains, Australia. Quaternary Research 55:179-189.

Barrows, T.T., J.O. Stone, L.K. Fifield and R.G. Cresswell 2002. The timing of the last glacial maximum in Australia. Quaternary Science Reviews 21:159-173.

Black, M.P., S.D. Mooney and H.A. Martin 2006. A >43,000-year vegetation and fire history from Lake Baraba, New South Wales, Australia. Quaternary Science Reviews 25:3003-3016

Bowler, J.M. and T. Hamada. 1971. Late Quaternary Stratigraphy and Radiocarbon Chronology of Water Level Fluctuations in Lake Keilambete, Victoria. Nature 232: 330-332.

Bowler, J.M., K-H. Wyrwoll and L. Yanchuou 2001. Variations of the northwest Australian summer monsoon over the last 300,000 years: the paleohydrological record of the Gregory (Mulan) Lakes System. Quaternary International 83-85:63-80.

Brereton, R., S. Bennett and I. Mansergh 1995. Enhanced greenhouse climate change and effects on selected fauna of south-eastern Australia: A trend analysis. Biological Conservation 72:339-354.

Catterall, C. and M. Kingsford 1993. Remnant bushland of south-east Queensland in the 1990s: its distribution, loss, ecological consequences and future prospects. Brisbane: Institute of Applied Environmental Research, Griffith University and Brisbane City Council.

Chen, X.Y., J.M. Bowler and J.W. Magee 1993. Late Cenozoic stratigraphy and hydrologic history of Lake Amadeus, a central Australian playa Australian Journal of Earth Sciences 40:1-14.

Chen, S.F., S.J. Rossiter, C.G. Faulkes and J. Jones 2006. Population genetic structure and demographic history of the endemic Formosan lesser horseshoe bat (Rhinolophus monoceros). Molecular Ecology 15:1643-1656.

Chivas, A.R., A. García, S. van der Kaars, M.J.J. Couapel, S. Holt, M.R. Reeves, D.J. Wheeler, A.D. Switzer, C.V. Murray-Wallace, D. Banerjee, D.M. Price, S.X. Wang, G. Pearson, N.T. Edgar, L. Beaufort, P. De Deckker, E. Lawson and C.B. Cecil 2001. Sea-level and environmental changes since the last interglacial in the Gulf of Carpentaria, Australia: an overview. Quaternary International 83-85:19-46.

Churchill, S.K. 2008. Australian Bats. Second edition. Sydney: Jacana Books, 255pp.

Collins, L. 1999. Wildlife caring and conservation: the effect of drought on the flying-foxes of the New South Wales north coast. Australasian Bat Society Newsletter 12:31-32.

Cook, E. 2009. A record of late Quaternary environments at lunette-lakes Bolac and Turangmoroke, Western Victoria, Australia, based on pollen and a range of non-pollen palynomorphs. Review of Palaeobotany and Palynology 153:185-224.

Crucifix, M., R.A. Betts and C.D. Hewitt 2005. Pre-industrial-potential and Last glacial maximum global vegetation simulated with a coupled climate-biosphere model: diagnosis of bioclimatic relationships. Global and Planetary Change 45:295-312.

D'Costa, D., J. Grindrod and R. Ogden 1993. Preliminary environmental reconstructions from Late Quaternary pollen and mollusc assemblages at Egg Lagoon, King Island, Bass Strait. Australian Journal of Ecology 18:351-366. 
Dickman, C. and M. Fleming 2002. Pest or passenger pigeon? The New South Wales Scientific Committee's assessment of the status of the Grey-headed flying-fox. In P. Eby and D. Lunney (eds) Managing the Grey-headed Flying-fox as a Threatened Species, pp2028. Sydney: Royal Zoological Society of New South Wales.

Divljan, A. 2008. Population ecology of the grey-headed flying-fox, Pteropus poliocephalus: a study of the age structure and the effects of mortality on a vulnerable species. Unpublished $\mathrm{PhD}$ thesis, Australia: University of Sydney.

Dodson, J.R. and R.V.S. Wright 1989. Humid to arid to subhumid vegetation shift on Pilliga Sandstone, Ulungra Springs, New South Wales. Quaternary Research 32:182-192.

Drummond, A.J. and A. Rambaut 2007. BEAST: Bayesian evolutionary analysis by sampling trees. BMC Evolutionary Biology 7:214.

Drummond, A.J., A. Rambaut, B. Shapiro and O.G. Pybus 2005. Bayesian coalescent inference of past population dynamics from molecular sequences. Molecular Biology and Evolution 22:1185-1192.

Duncan, A., G.B. Baker and N. Montgomery 1999. Action Plan for Australian Bats. http:// www.environment.gov.au/biodiversity/threatened/publications/action/bats/index.html

Eby, P. 1991. Seasonal movements of grey-headed flying-foxes, Pteropus poliocephalus (Chiroptera: Pteropodidae), from two maternity camps in northern New South Wales. Wildlife Research 18:547-559.

Eby, P. 1991. Low reproductive output in grey-headed flying-fox associated with a short period of food scarcity. Australasian Bat Society Newsletter 14:17-20.

Eby, P. 1998. An analysis of diet specialization in frugivorous Pteropus poliocephalus (Megachiroptera) in Australian subtropical rainforest. Australian Journal of Ecology 23:443-456.

Eby, P., G. Richards, L. Collins and K. Parry-Jones 1999. The distribution, abundance and vulnerability to population reduction of a nomadic nectarivore, the grey- headed flyingfox Pteropus poliocephalus in New South Wales during a period of resource concentration. Australian Zoologist 31:240-243.

Eby, P. 2004. National count of grey-headed flying foxes April 3 \& 4, 2004. A report to the Department of Environment and Heritage, Canberra.

Excoffier, L., G. Laval and S. Schneider 2005. ARLEQUIN (version 3.0): an integrated software package for population genetics data analysis. Evolutionary Infomatics Online 1:47-50.

Farquhar, G.D. 1997. Carbon dioxide and vegetation. Science 278:1411-1413.

Field, J.H., J.R. Dodson and I.R. Prosser 2002. A Late Pleistocene vegetation history from the Australian semi-arid zone. Quaternary Science Reviews 21:1023-1037.

Fox, S.J. 2006. Population structure in the spectacled flying-fox, Pteropus conspicillatus: a study of genetic and demographic factors. Unpublished PhD thesis, School of Marine and Tropical Biology, James Cook University, Queensland, Australia.

Fox, S.J., K. Parry-Jones, D. Blair, J.G. Luly, A. Divjlan and G. Wardle, In prep. Panmixia in the grey-headed flying-fox in New South Wales inferred using mitochondrial and nuclear markers.

Fox, S.J., J.G. Luly, C.B. Mitchell, J. Maclean and D.A. Westcott 2008. Demographic indications of decline in the spectacled flying-fox (Pteropus conspicillatus) on the Atherton Tablelands of northern Queensland. Wildlife Research 35:417-424.

Fox, S., H. Spencer and G. O’Brien 2008. Analysis of twinning in flying-foxes (Megachiroptera) reveals superfoetation and multiple paternity. Acta Chiropterologica 10:271-278.

Galloway, R.W. 1965. Late Quaternary climates in Australia. Journal of Geology 73:603-618.

Graham, C.H., C. Moritz and S.E. Williams 2006. Habitat history improves prediction of biodiversity in rainforest fauna. Proceedings of the National Academy of Sciences USA 103:632636. 
Hall, L. and G. Richards 2000. Flying-foxes. Fruit and blossom bats of Australia. Sydney: University of New South Wales Press. 135pp.

Harle, K.J. 1997. Late Quaternary vegetation and climate change in southeastern Australia: palynological evidence from marine core E55-6. Palaeogeography, Palaeoclimatology, Palaeoecology 131:465-483.

Harpending, H.C. 1994. Signature of ancient population growth in a low-resolution mitochondrial mismatch distribution. Human Biology 66:591-600.

Hasegawa, M., H. Kishino and Y. Yano 1985. Dating of the human-ape splitting by a molecular clock of mitochondrial DNA. Journal of Molecular Evolution 22:160-174.

Hay, J.M., S. Subramanian, C.D. Millar, E. Mohandesan and D.M. Lambert 2008. Rapid molecular evolution in a living fossil. Trends in Genetics 24:106-109.

Hesse, P., G.S. Humphreys, P.M. Selkirk, D.A. Adamson, D.B. Gore, D.C. Nobes, D.M. Price, J.-L. Schwenninger, B. Smith, M. Tulau and F. Hemmings 2003. Late Quaternary aeolian dunes on the presently humid Blue Mountains, Eastern Australia. Quaternary International 108:13-32.

Hesse, P. P. 1994. The record of continental dust from Australia in Tasman Sea sediments. Quaternary Science Reviews 13:257-272.

Hofreiter, M. and J. Stewart 2009. Ecological change, range fluctuations and population dynamics during the Pleistocene. Current Biology 19:R584-R594.

Hope, G.S. 1978. The Late Pleistocene and Holocene vegetational history of Hunter Island, northwestern Tasmania. Australian Journal of Botany 26:490-514.

Hope, G.S. 1994. Quaternary vegetation. In R. Hill (ed.) Australian Vegetation: Cretaceous to Recent pp368-389. Cambridge UK: Cambridge University Press.

Hope, G.S., A.P. Kershaw, S. van der Kaars, X-J. Sun, P.-M. Liew, L.E. Heusser, H. Tahahara, M. McGlone, N. Miyoshi, and P.T. Moss 2005. History of vegetation and habitat change in the Austral-Asian region. Quaternary International 118-119:103-126.

Hope, P. 2005. The Weather and Climate of Australia at the Last glacial maximum. Unpublished PhD Thesis, School of Earth Sciences, University of Melbourne, 266pp.

Hughes, L., E.M. Causey and M. Westoby 1996. Climatic range of Eucalyptus species in relation to future climate change. Global Ecology and Biogeography Letters 5:23-29.

Kenyon, C.E. 1989. A late Pleistocene and Holocene pollen diagram from Boulder Flat, east Gippsland. Unpublished BSc (Hons.) thesis, Department of Botany, Monash University.

Kershaw, A.P. 1986. Climatic-change and aboriginal burning in Northeast Australia during the last two glacial interglacial cycles. Nature 322:47-49.

Kershaw, A.P. 1995. Environmental change in greater Australia. Antiquity 69:656-675.

Law, B., L. Mackowski, L Schoer and T. Tweedie 2000. Flowering phenology of myrtaceous trees and their relation to climatic, environmental and disturbance variables in northern New South Wales. Austral Ecology 25:165-178.

Law, B., P. Eby and D. Somerville 2002. Tree planting to conserve flying-foxes and reduce orchard damage. In P. Eby and D. Lunney (eds) Managing the Grey-headed Flying-fox as a Threatened Species, pp84-94. Sydney: Royal Zoological Society of New South Wales.

Longmore, M.E. 1997. Quaternary palynological records from perched lake sediments, Fraser Island, Queensland, Australia: rainforest, forest history and climatic control. Australian Journal of Botany 45:507-526.

Longmore, M.E. and H. Heijnis 1999. Aridity in Australia: Pleistocene records of palaeohydrological and palaeoecological change from the perched lake sediments of Fraser Island, Queensland, Australia. Quaternary International 57-58:35-47.

Luly, J.G. 1993. Holocene palaeoenvironments near Lake Tyrrell, semi-arid northwestern Victoria, Australia. Journal of Biogeography 20:587-596. 
Magee, J.W., G.W. Miller, N.A. Spooner and D. Questiaux 2004. Continuous 150 k.y. monsoon record from Lake Eyre, Australia: Insolation-forcing implications and unexpected Holocene failure. Geology 32:885-888.

Martin, L., P.A. Towers, M.A. McGuckin, L. Little, H. Luckhoff and A.W. Blackshaw 1985. Reproductive biology of flying-foxes (Chiroptera: Pteropodidae). Australian Mammalogy 10:115-118.

Martin, L. and A.P. Mcllwee 2002. The reproductive biology and intrinsic capacity for increase of the Grey-headed Flying-fox Pteropus poliocephalus (Megachiroptera), and the implications of culling. In P. Eby and D. Lunney (eds) Managing the Grey-headed Flying-fox as a Threatened Species, pp91-108. Sydney: Royal Zoological Society of New South Wales.

McConkey, K.R. and D. R. Drake 2006. Flying-foxes cease to function as seed dispersers long before they become rare. Ecology 87:271-276.

McDonald-Madden, E., G.S.G. Schreiber, D.M. Forsyth, D. Choquenot and T.F. Clancy 2005. Factors affecting grey-headed flying-fox (Pteropus poliocephalus: Pteropodidae) foraging in the Melbourne metropolitan area, Australia. Austral Ecology 30:600-608.

McIlwee, A. and L. Martin 2002. On the intrinsic capacity for increase of Australian flyingfoxes (Pteropus spp. Megachiroptera). Australian Zoologist 32:76-100.

McKenzie, G.M. and A.P. Kershaw 2000. The last glacial cycle from Wyelangta, the Otway region of Victoria, Australia. Palaeogeography, Palaeoclimatology, Palaeoecology 155:177-193.

McMahon, J.P., M.F. Hutchinson, H.A. Nix and K.D. Ord 1995. ANUCLIM user's guide, version 1. Canberra: Centre for Resource and Environmental Studies, Australian National University.

Miller, G.H., J.W. Magee and A.J.T. Jull 1997. Low-latitude glacial cooling in the Southern Hemisphere from amino-acid racemisation in emu egg shells. Nature 385:241-244.

Moravek, S., J.G. Luly, J.F. Grindrod, R.J. Fairfax, R.J. Fensham and S.S. Smithers In prep. Origin and development of the grassy bald at Dandabah, Bunya Mountains, southeastern Queensland, Australia.

Moss, P.T. and A.P. Kershaw 2000. The last glacial cycle from the humid tropics of northeastern Australia: comparison of a terrestrial and marine record. Palaeogeography, Palaeoclimatology, Palaeoecology 155:155-176.

O'Brien, G.M. 1993. Seasonal reproduction in flying-foxes, reviewed in the context of other tropical mammals. Reproduction, Fertility, Development 5:499-521.

Parris, K.M. and D.L. Hazell 2005. Biotic effects of climate change in urban environments: The case of the grey-headed flying-fox (Pteropus poliocephalus) in Melbourne, Australia. Biological Conservation 124:267-276.

Parry-Jones, K. and M.L. Augee 1991. Food selection by grey-headed flying-foxes (Pteropus poliocephalus) occupying a summer colony site near Gosford, New South Wales. Wildlife Research 18:111-124.

Parry-Jones, K.A. and M.L. Augee 1992. Movements of Grey-headed flying-foxes (Pteropus poliocephalus) to and from a colony site on the central coast of New South Wales. Wildlife Research 19:331-340.

Parry-Jones, K.A. and M.L. Augee 2001. Factors affecting the occupation of a colony site in Sydney, New South Wales by the grey-headed flying-fox Pteropus poliocephalus (Pteropodidae). Austral Ecology 26:47-55.

Parsons, J.G., S.K.A. Robson and L.A. Shilton 2008. One for all and all four one! First report of all four Pteropus species co-roosting at one site in Australia. Australasian Bat Society Newsletter 31:10.

Parsons, J.G., S.K.A. Robson, L.A. Shilton and J. VanDerWal. 2010. The distribution of flying fox camps in Australia: new perspectives in a changing climate. In preparation. 
Phillips, S. J., M. Dudik and R. Schapire 2006. MaxEnt, version 2. AT\&T Labs-Research, Princeton University, and the Centre for Biodiversity and Conservation, American Museum of Natural History.

Posada, D. and K.A. Crandall. 1998. MODELTEST: testing the model of DNA substitution Bioinformatics 14: 817-818.

Ratcliffe, F.N. 1931. The Flying-fox (Pteropus) in Australia. CSIR Bulletin No. 53 Melbourne.

Ratcliffe, F.N. 1932. Notes on the fruit bats (Pteropus spp.) of Australia. The Journal of Animal Ecology 1:32-57.

Roberts, B.J., C.P. Catterall, J. Kanowski and P. Eby 2008. A re-evaluation of the northern distributional limit of the Grey-headed Flying-fox, Pteropus poliocephalus. Australasian Bat Society Newsletter 31:16-19.

Rogers, A.R. and H. Harpending 1992. Population growth makes waves in the distribution of pairwise genetic differences. Molecular Biology and Evolution 9:552-569.

Singh, G. and E.A. Geissler 1985. Late Cainozoic history of vegetation, fire, lake levels and climate at Lake George, New South Wales, Australia. Philosophical Transactions of the Royal Society of London B 311:379-477.

Tidemann, C.R. 1999. The biology and management of the Grey-headed Flying-fox. Acta Chiropterologica 1:151-164.

Tidemann, C.R. and J.C. Nelson 2004. Long-distance movements of the grey-headed flyingfox (Pteropus poliocephalus). Journal of the Zoological Society of London 263:141-146.

Thomas, I. et al 2001.

Torgersen, T., J.G. Luly, P. De Deckker, M.R. Jones, D.E. Searle and W.J. Ullman 1988. Late Quaternary environments of the Carpentaria Basin, Australia. Palaeogeography, Palaeoclimatology, Palaeoecology 67:245-261.

Van Der Wal, J., L. Shoo and S.E. Williams 2009. New approaches to understanding late Quaternary climate fluctuations and refugial dynamics in Australian wet tropical rainforests. Journal of Biogeography 36:291-301.

Walker, B.H. 1992. Biodiversity and ecological redundancy. Conservation Biology 6:18-23.

Wasson, R.J. 1983. The Cainozic history of the Strzelecki and Simpson dunefields. Zeitschrift für Geomorphologie N.F., Supplement Band 45:85-115.

Webb, L.J. 1964. An historical interpretation of the grass balds of the Bunya Mountains, south Queensland. Ecology 45:159-62.

Webb, N.J. and C.R. Tidemann 1996. Mobility of Australian flying-foxes, Pteropus spp. (Megachiroptera): evidence from genetic variation. Proceedings of the Royal Society Biological Sciences 263:497-502.

Welbergen, J., S.M. Klose, N. Markus and P. Eby 2008. Climate change and the effects of temperature extremes on Australian flying-foxes. Proceedings of the Royal Society $B$ 275:419-425.

Williams, S. and J. Middleton 2008. Climatic seasonality, resource bottlenecks and abundance of rainforest birds: implications for global climate change. Diversity and Distributions 14:69-77.

Williams, S.E., E.E. Bolitho and S. Fox 2003. Climate change in Australian tropical rainforests: an impending environmental catastrophe. Proceedings of the Royal Society of London Series B-Biological Sciences 270:1887-1892.

Williams, N.S.G., M.J. McDonnell, G.K. Phelan, L.D. Keim and R. van der Ree 2006. Range expansion due to urbanisation: Increased food resources attract, Grey-headed Flying-foxes (Pteropus poliocephalus) to Melbourne. Austral Ecology 31:190-198.

Worthington Wilmer, J. and E.M. Barratt 1996. A non-lethal method of tissue sampling for genetic studies of Chiropterans. Bat Research News 37:1-3. 
Yokoyama, Y., A. Purcell, K. Lambeck and P. Johnson 2001. Shore-line reconstructions around Australia during the Last glacial maximum and Late Glacial Stage. Quaternary International 83-85:9-18. 